\title{
Zintl behavior and vacancy formation in type-I Ba-Al-Ge clathrates
}

\author{
Sergio Y. Rodriguez, Laziz Saribaev, and Joseph H. Ross, Jr. \\ Department of Physics, Texas A\&M University, College Station, Texas 77843-4242, USA \\ (Received 31 May 2010; revised manuscript received 25 July 2010; published 24 August 2010)
}

\begin{abstract}
In a study of type-I $\mathrm{Ba}_{8} \mathrm{Al}_{x} \mathrm{Ge}_{46-x}$ clathrates for $4 \leq x \leq 16$, several samples with different stoichiometric compositions were prepared and measured. Here we report wavelength dispersion spectroscopy, powder x-ray diffraction and resistivity measurements, coupled with first-principles calculations. The lattice constant and vacancy count showed linear behavior for low Al content, extrapolating to the values for $\mathrm{Ba}_{8} \mathrm{Ge}_{43}$ as $x \rightarrow 0$, with the $x=4$ sample exhibiting a superstructure identical to that of $\mathrm{Ba}_{8} \mathrm{Ge}_{43}$. In ab initio calculations we identified the most stable configurations and examined energy differences for departures from Zintl behavior. We found the energy barrier for off-Zintl compositions to be relatively low and attributed this to the presence of a pseudogap near the Fermi energy.
\end{abstract}

DOI: 10.1103/PhysRevB.82.064111

PACS number(s): 61.72.jd, 82.75.-z, 71.20.Nr

\section{INTRODUCTION}

Semiconductor clathrates consist of $\mathrm{Si}, \mathrm{Ge}$, or $\mathrm{Sn}$ open $s p^{3}$ framework networks with guest atoms inside. Clathrates have gained considerable attention due to their thermal and electrical properties, and potential for thermoelectric device application. ${ }^{1-5}$ These materials have shown interesting properties such as rattling of the guest atoms at low frequencies, ${ }^{6}$ and carrier densities can also be adjusted, ${ }^{7}$ making them particularly attractive for potential applications. Sometimes even the structure can be tuned as in the case of $\mathrm{Ba}_{8} \mathrm{Ga}_{16} \mathrm{Sn}_{30} .{ }^{8}$ Recently much work has been devoted to $\mathrm{Ba}_{8} \mathrm{Ga}_{16} \mathrm{Ge}_{30}$, which exhibits a particularly large thermoelectric efficiency at high temperatures. However the change in molar ratio $(\mathrm{Ga} / \mathrm{Ge})$ leads to a large variation in thermoelectric properties. ${ }^{9} 10$ In the case of $\mathrm{Ba}-\mathrm{Al}-\mathrm{Ge}$ clathrates the electric and thermal properties are affected by the partial substitution of the framework atoms with metallic species. ${ }^{11,12}$ Therefore a full description of the behavior as a function of the $\mathrm{Al}$ substitution will help in the understanding of vacancy formation and $\mathrm{Al}$ framework occupation.

For this study we considered $\mathrm{Ba}-\mathrm{Al}-\mathrm{Ge}$ clathrates as a function of $\mathrm{Al}$ substitution. We studied $\mathrm{Ba}_{8} \mathrm{Al}_{x} \mathrm{Ge}_{46-x-y} \square_{y}$ for $4 \leq x \leq 16$, where $\square$ represents a vacancy to understand the Al preferential site occupation and vacancy occurrence. For large $x$, this material crystallizes as a type-I clathrate. In this important clathrate structure each unit cell consists of six hexakaidecahedral cages and two dodecahedral cages. For $x=0$, this material forms an ordered superstructure with composition $\mathrm{Ba}_{8} \mathrm{Ge}_{43}$, with three vacancies on the $6 c$ site, arranged in a helical path along the [100] directions. ${ }^{13,14}$ For low Al concentration we may thus expect to observe this behavior.

In a Zintl material such as $\mathrm{Ba}_{8} \mathrm{Al}_{16} \mathrm{Ge}_{30}$ the more electropositive "guest" atoms donate their valence electrons to the more electronegative "host" (or cage) atoms such that the latter complete their valence requirement (octet rule) and build a covalently bonded cage structure. The appearance of spontaneous vacancies as in the case of $\mathrm{Ba}_{8} \mathrm{Ge}_{43} \square_{3}$ (Ref. 15) can serve to maintain electron charge balance in offstoichiometry materials. In the case of $\mathrm{Ba}_{8} \mathrm{Al}_{x} \mathrm{Ge}_{46-x}$, near $x=16$ spontaneous vacancies also appear, even though $x=16$ should be an ideal Zintl phase. Vacancy formation affects the electronic and transport properties significantly. Therefore it is important to know what is the vacancy variation as a function of $\mathrm{Al}$ substitution and also it is meaningful to obtain the framework $\mathrm{Al}$ occupation to get a better understanding of the changes in electrical and transport properties.

Thus we studied a series of $\mathrm{Ba}_{8} \mathrm{Al}_{x} \mathrm{Ge}_{46-y}$ materials examining their composition and structures vs $x$. We used wavelength dispersion spectroscopy (WDS, an electron microprobe method) and $\mathrm{x}$-ray diffraction (XRD) measurements to characterize these materials. In addition, first-principles calculations were carried out to examine the deficit of framework occupation observed in these samples. These calculations examined local variations in electronic behavior as the $\mathrm{Al}$ composition was varied and vacancies formed. Total formation energies are reported for different $\mathrm{Al}$ occupation of the framework sites.

\section{EXPERIMENTAL AND COMPUTATIONAL METHODS}

Several samples of nominal composition $\mathrm{Ba}_{8} \mathrm{Al}_{x} \mathrm{Ge}_{46-x}$ with $4 \leq x \leq 16$ were prepared from the pure elements mixed according to the desired compositions and arc-melted in argon following by annealing at $900{ }^{\circ} \mathrm{C}$ for $100 \mathrm{~h}$. Five different samples with stoichiometric starting compositions $x=4$, $8,12,14$, and 16 were prepared. XRD measurements at room temperature were performed using a Bruker D8 x-ray powder diffractometer. Rietveld refinement was performed using EXPGUI. ${ }^{16}$ WDS measurements were done in a Cameca SX50 equipped with four wavelength-dispersive $\mathrm{x}$-ray spectrometers. Four-probe resistivity measurements were performed using a Quantum Design Physical Property Measurement System from room temperature to $2 \mathrm{~K}$.

First-principles calculations were implemented with the full-potential linearized augmented plane-wave (LAPW) method as implemented in the WIEN2K code ${ }^{17}$ within the generalized gradient approximation. The Perdew-BurkeErnzerhof formalism was used for the exchange-correlation term. All superstructures were minimized in volume and internal structural parameters.

\section{EXPERIMENTAL RESULTS}

From WDS and XRD measurements we find that for $x$ $=8$ and $x=16$, the samples are type-I clathrates with an ad- 
TABLE I. Number of atoms and vacancies per unit cell obtained by WDS measurements for $\mathrm{Ba}_{8-z} \mathrm{Al}_{x} \mathrm{Ge}_{46-y}$.

\begin{tabular}{ccccc}
\hline \hline Sample & $\mathrm{Ba}$ & $\mathrm{Al}$ & $\mathrm{Ge}$ & No. of vacancies \\
\hline 4 & 8 & 4.10 & 39.60 & 2.3 \\
8 & 8 & 7.37 & 37.12 & 1.5 \\
12 & $7.91 \pm 0.09$ & 9.00 & 35.82 & $1.2 \pm 0.5$ \\
14 & $7.84 \pm 0.10$ & 11.15 & 34.29 & $0.6 \pm 0.6$ \\
16 & $7.83 \pm 0.03$ & 14.28 & 31.54 & $0.2 \pm 0.2$ \\
\hline \hline
\end{tabular}

ditional small amount of diamond structure Ge. In the $x$ $=12$ and 14 samples an additional minor phase was seen, apparently an oxide of $\mathrm{Ba}$ and $\mathrm{Al}$. Finally the $x=4$ sample also exhibited superstructure reflections identical to those of $\mathrm{Ba}_{8} \mathrm{Ge}_{43} \square_{3}$. From WDS measurements all the samples showed a lower Al concentration than the expected stoichiometric compositions. Samples are denoted by $\mathrm{Al}_{x}$ according to the starting compositions, for example, $\mathrm{Al}_{16}$ representing $\mathrm{Ba}_{8} \mathrm{Al}_{16} \mathrm{Ge}_{30}$.

In scans of our samples by WDS we scaled the clathratephase atomic percentages to obtain the total number of $\mathrm{Ba}$, $\mathrm{Al}$, and $\mathrm{Ge}$ atoms per cell. In the case of $\mathrm{Al}_{4}$ and $\mathrm{Al}_{8}$ we set the $\mathrm{Ba}$ sites to be completely full. For $\mathrm{Al}_{12}, \mathrm{Al}_{14}$, and $\mathrm{Al}_{16}$ it was not possible to have complete $\mathrm{Ba}$ site occupation, and thus we found a range of possible $\mathrm{Ba}, \mathrm{Al}$, and $\mathrm{Ge}$ concentrations. The upper bound was determined by full framework occupation and the lower bound following an electron balance according to the theoretical Zintl concept. The center value corresponded to a smooth variation in the WDS scaling factor, as expected. The results are summarized in Table I.

From XRD measurements, as described above we found that for $x=8$ and higher there were only type-I reflections. The data obtained from Rietveld refinements are summarized in Table II. Lattice constants gradually decreased from $10.849 \AA$ for $\mathrm{Al}_{16}$ to $10.716 \AA$ for $\mathrm{Al}_{4}$. For $\mathrm{Al}_{16}$ the obtained value is similar to the values reported by Christensen et al., ${ }^{11}$ for various growth techniques. $\mathrm{Al}_{4}$ exhibits a symmetry similar to that of the defect clathrate $\mathrm{Ba}_{8} \mathrm{Ge}_{43} \square_{3}$ where there are extra peaks in the XRD spectrum due to ordering of vacancies. In this case the symmetry is changed from the ideal type-I clathrate structure $(P m \overline{3} n)$ to a $(2 \times 2 \times 2)$ cubic superstructure having symmetry $(I a \overline{3} d) .{ }^{18}$ The Rietveld refinement in this case was done for the superstructure $(I a \overline{3} d)$ and the $\mathrm{Al}$ content was given by a sum of the respective

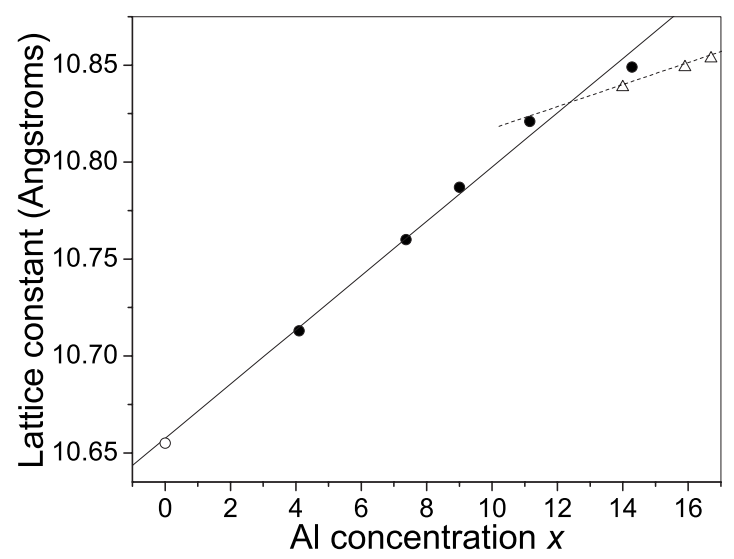

FIG. 1. Lattice constant as a function of Al doping. Filled circles correspond to our measured samples. Hollow circle is the reported value for $\mathrm{Ba}_{8} \mathrm{Ge}_{43}$ (Ref. 18) and hollow triangles correspond to samples measured by Christensen and Iverson (Ref. 11). Lines correspond to linear fits described in text.

type-I parent sites. The lattice constant was divided by 2 to compare with the type-I structures.

Combining the results from XRD and WDS measurements, the lattice constant shows a linear behavior as a function of $\mathrm{Al}$ substitution for low $\mathrm{Al}$, as shown in Fig. 1, where the solid line is a linear fit to low Al content samples. The hollow circle is the reported value for $\mathrm{Ba}_{8} \mathrm{Ge}_{43} \cdot{ }^{18}$ This reported value is in close agreement with a linear extrapolation to zero $\mathrm{Al}$ content. The hollow triangles are the values reported by Christensen and Iverson ${ }^{11}$ In this case the high $\mathrm{Al}$ content values appear to go over to a different slope compared to those for low Al content. The dashed line corresponds to a linear fit to the values reported by Christensen and Iverson ${ }^{11}$ and our two highest $\mathrm{Al}$ content samples.

The Al occupation of framework sites obtained from XRD on $\mathrm{Al}_{16}$ (Table II) follows closely the relationship from a previous study on $\mathrm{Al}_{16},{ }^{19}$ where the best description of the NMR line shape was for a configuration of 3, 4, and $9 \mathrm{Al}$ on the $6 c, 16 i$, and $24 k$ sites, respectively. These are close to the values obtained from Rietveld refinements.

A feature of $\mathrm{Ba}_{8} \mathrm{Al}_{x} \mathrm{Ge}_{46-y}$ is the occurrence of spontaneous vacancies to balance the electron count in the framework, according to the Zintl concept. ${ }^{20}$ For example, for $\mathrm{Al}_{12}$ the theoretical Zintl composition is $\mathrm{Ba}_{8} \mathrm{Al}_{12} \mathrm{Ge}_{33} \square_{1}$, since if each $\mathrm{Ba}$ donates two electrons and $\mathrm{Al}$ has valence 3, there are four excess framework electrons per cell after filling all bonds, enough to fill the nonbonding orbitals adjoining a

TABLE II. Al framework occupation obtained by XRD measurements at room temperature for $\mathrm{Ba}_{8-z} \mathrm{Al}_{x} \mathrm{Ge}_{46-y}$, along with the lattice constant, and the goodness of fit.

\begin{tabular}{ccccccc}
\hline \hline Sample & $6 c$ & $16 i$ & $24 k$ & $\begin{array}{c}a \\
(\AA)\end{array}$ & $W R_{p}$ & $R_{p}$ \\
\hline 4 & 0.86 & 1.62 & 0.80 & 10.716 & 0.1793 & 0.1201 \\
8 & 1.20 & 1.00 & 4.99 & 10.760 & 0.1933 & 0.1306 \\
12 & 1.99 & 3.73 & 5.92 & 10.787 & 0.1873 & 0.1369 \\
14 & 3.18 & 0.77 & 7.97 & 10.821 & 0.1449 & 0.1088 \\
16 & 3.01 & 2.66 & 10.22 & 10.849 & 0.0473 & 0.0359 \\
\hline \hline
\end{tabular}




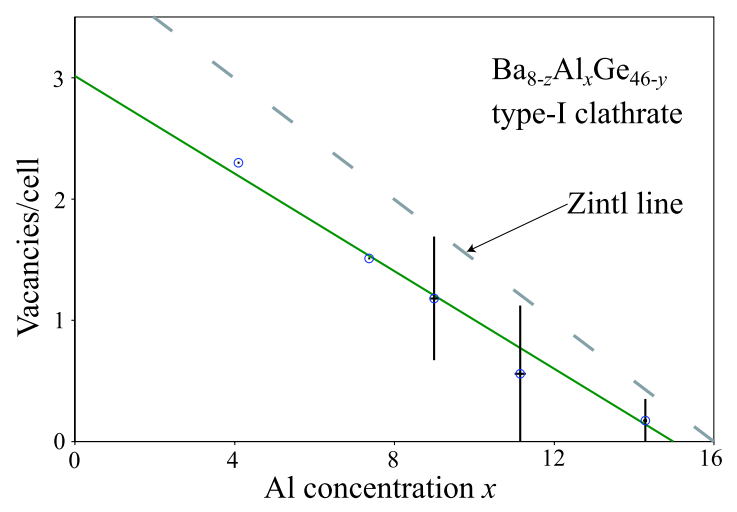

FIG. 2. (Color online) Number of vacancies as a function of $\mathrm{Al}$ doping. Continuous line is a linear fit to the data. Zintl line is also included as a reference. Horizontal and vertical error bars as described in text.

single vacancy. The expected result is a semiconductor or low-carrier density material. For $\mathrm{Ba}_{8} \mathrm{Al}_{16} \mathrm{Ge}_{30}$ one expects a balanced framework electron count and no spontaneous vacancies, while as the $\mathrm{Al}$ content decreases the vacancy count should increase, the limiting case being the ordered superstructure $\mathrm{Ba}_{8} \mathrm{Ge}_{43} \square_{3}$. However, the latter composition does not correspond to a Zintl compound because it exhibits one less vacancy than expected. For comparison in $\mathrm{Ba}_{8} \mathrm{Ga}_{x} \mathrm{Ge}_{46-y}$ the vacancy count was determined to be about half the expected Zintl value over a range of compositions. ${ }^{14}$

The variation in vacancy count as a function of $\mathrm{Al}$ concentration is shown in Fig. 2. The number of vacancies per cell varies from 0.2 for $\mathrm{Al}_{16}$ to 2.3 for $\mathrm{Al}_{4}$. A straight-line fit extends from 3.0 vacancies for $x=0$ to 0 vacancies at $x$ $=15.0$. Thus the vacancy count smoothly approaches a limiting value equivalent to that of $\mathrm{Ba}_{8} \mathrm{Ge}_{43}$. The uncertainty in vacancy count is relatively large for large $x$, even though the uncertainty in $x$ (horizontal bars) is small. However the values connect smoothly to those for low $x$ and remain below the theoretical Zintl line.

In resistivity measurements we studied polycrystalline bars cut from the ingots with lengths between 3 and $6 \mathrm{~mm}$. All samples exhibited positive temperature coefficients, typical of metals or heavily doped semiconductors, with, for example, $\mathrm{Al}_{16}$ having a low-temperature value of $376 \mu \Omega \mathrm{cm}$, within the range observed previously for $\mathrm{Ba}_{8} \mathrm{Al}_{16} \mathrm{Ge}_{30}$ samples. ${ }^{11}$ As the number of $\mathrm{Al}$ decreases the resistivity diminishes. For $\mathrm{Al}_{4}$ the low-temperature values are similar to those reported for $\mathrm{Ba}_{8} \mathrm{Ge}_{43},{ }^{21,22}$ but $\mathrm{Ba}_{8} \mathrm{Ge}_{43}$ has a steeper slope, so that at room temperature the resistivity for $\mathrm{Ba}_{8} \mathrm{Ge}_{43}$ is almost five times larger. ${ }^{21,22}$ The behavior vs $\mathrm{Al}$ content matches the expected behavior for increased deviation from Zintl behavior thus increasing carrier density with decreasing $x$. The solid curves are fits to the data assuming a BlochGrüneisen function for pure electron-phonon scattering, ${ }^{23}$ for which the fitted values of the Debye temperature are $380 \mathrm{~K}$ for $\mathrm{Al}_{16}$ and $\mathrm{Al}_{4}$, and $330 \mathrm{~K}$ for $\mathrm{Al}_{8}$, Fig. 3 .

\section{COMPUTATIONAL RESULTS AND DISCUSSION}

$A b$ initio calculations were done for analysis of the electronic structure and to understand the stability of the differ-

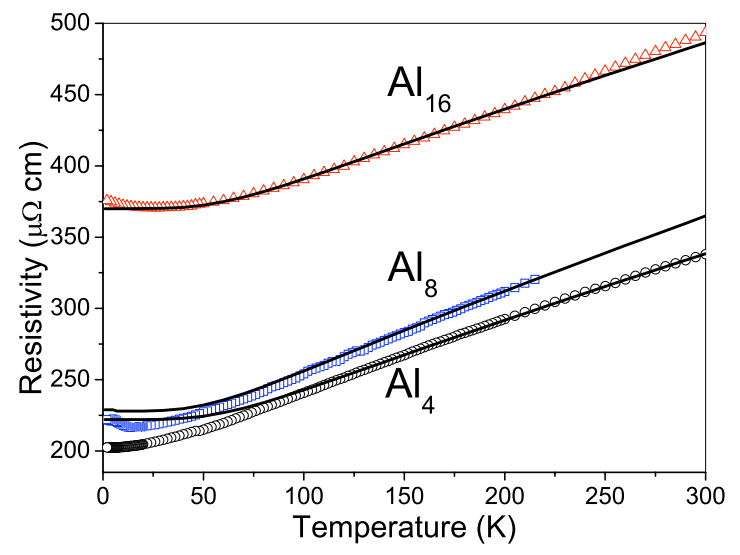

FIG. 3. (Color online) Resistivity as a function of temperature for $\mathrm{Al}_{4}, \mathrm{Al}_{8}$, and $\mathrm{Al}_{16}$. Solid curves: Bloch-Grüneisen fits.

ent configurations. We considered more than 16 different superstructures with several framework arrangements and a range of $\mathrm{Al}$ occupation. All superstructures were minimized in volume and internal structural parameters.

A linear extrapolation of the measured number of vacancies as a function of $\mathrm{Al}$ concentration, for low $x$, intercepts 0 vacancies for $x$ close to 15 as shown in Fig. 2. This is less than the expected value for the Zintl composition, $\mathrm{Ba}_{8} \mathrm{Al}_{16} \mathrm{Ge}_{30}$. To study this behavior, we examined a number of filled-framework structures with fewer than $16 \mathrm{Al}$ per cell.

Formation energies were obtained from the equation,

$$
\begin{aligned}
E_{\text {form }}\left(\mathrm{Ba}_{8} \mathrm{Al}_{x} \mathrm{Ge}_{46-x}\right)= & E_{\mathrm{Ba}_{8} \mathrm{Al} \mathrm{Ge}_{46-x}}-8 E_{\mathrm{Ba}}-x E_{\mathrm{Al}} \\
& -(46-x) E_{\mathrm{Ge}},
\end{aligned}
$$

where $x$ is the number of $\mathrm{Al}$ per unit cell. Cases we considered included $x=16,15,14$, and $12 . E_{\mathrm{Ba}}$ is the energy per $\mathrm{Ba}$ atom in Ba metal and similarly for the others.

The lowest-energy configurations obtained are summarized in Table III, where the first column is the total number of $\mathrm{Al}$ per unit cell, the next three columns indicate the $\mathrm{Al}$ framework occupation on the $6 c, 16 i$, and $24 k$ parent sites, and the fifth column is the total calculated formation energy relative to the lowest energy. The occupation of three $\mathrm{Al}$ on the $6 c$ site has been found to be the preferred value from computations as reported for Ba-Al-Ge, ${ }^{19} \mathrm{Ba}-\mathrm{Ga}-\mathrm{Ge},{ }^{24}$ and Ba-Ga-Sn (Ref. 25) clathrates. Some configurations with 2 and $4 \mathrm{Al}$ on the $6 c$ site (not shown here) were also considered but their energies were much higher than for those with $3 \mathrm{Al}$. The number of $\mathrm{Al}$ on the $16 i$ site was varied systematically from 1 to 5 with respective changes in the $24 k$ site.

As shown in Table III we found that among zero-vacancy configurations 3-1-12 was lowest in energy, where the three numbers refer to the first three columns in Table III. Energies are given relative to that of the 3-1-12 configuration, whose formation energy is $-17.9 \mathrm{eV}$. This is somewhat smaller than previously reported for $\mathrm{Ba}_{8} \mathrm{Al}_{16} \mathrm{Ge}_{30},{ }^{26}$ using a different functional. The 3-1-12 configuration was shown previously ${ }^{19}$ to have the lowest energy specifically for $\mathrm{Al}_{16}$ configurations, and also for $\mathrm{Ba}_{8} \mathrm{Ga}_{16} \mathrm{Ge}_{30}$ (Ref. 24) and $\mathrm{Ba}_{8} \mathrm{Ga}_{16} \mathrm{Sn}_{30} \cdot{ }^{25}$

From Table III it is seen that several configurations are rather close in energy to the 3-1-12 configuration with the 
TABLE III. Al framework occupation per formula unit used in calculations of $\mathrm{Ba}_{8} \mathrm{Al}_{x} \mathrm{Ge}_{46-x}$, for configurations with no $\mathrm{Al}-\mathrm{Al}$ pairs, and the calculated difference of total formation energy per formula unit with respect to lowest energy configuration, 3-1-12.

\begin{tabular}{rrrrr}
\hline \hline$x$ & $6 c$ & $16 i$ & $24 k$ & $\begin{array}{c}\Delta E \\
(\mathrm{eV})\end{array}$ \\
\hline 16 & 3 & 1 & 12 & 0.000 \\
16 & 3 & 2 & 11 & 0.027 \\
16 & 3 & 3 & 10 & 0.074 \\
16 & 3 & 4 & 9 & 0.126 \\
16 & 3 & 5 & 8 & 0.164 \\
15 & 3 & 1 & 11 & 0.275 \\
15 & 3 & 2 & 10 & 0.344 \\
15 & 3 & 3 & 9 & 0.736 \\
15 & 3 & 4 & 8 & 0.390 \\
15 & 3 & 5 & 7 & 0.452 \\
14 & 3 & 1 & 10 & 0.734 \\
14 & 3 & 2 & 9 & 0.750 \\
14 & 3 & 3 & 8 & 0.692 \\
14 & 3 & 4 & 7 & 0.739 \\
14 & 3 & 5 & 6 & 0.828 \\
12 & 3 & 1 & 8 & 1.606 \\
\hline \hline
\end{tabular}

difference between the lowest-energy $x=16$ configurations appearing hardly significant. However the preference for the 3-1-12 configuration is consistent with previous studies for $\mathrm{Ba}_{8} \mathrm{Ga}_{16} \mathrm{Ge}_{30}$ (Ref. 24) and $\mathrm{Ba}_{8} \mathrm{Ga}_{16} \mathrm{Sn}_{30},{ }^{25}$ where this configuration was also found to be preferred. The $x=15$ configuration 3-1-11 has a formation energy roughly $2 \%$ higher than that of 3-1-12; this difference is $0.006 \mathrm{eV} /$ atom, corresponding to a temperature of about $70 \mathrm{~K}$, much less than the growth temperature. Thus though the Zintl $x=16$ configurations have the lowest computed energies, it appears that $n$-type $x=15$ and 14 configurations may readily form with little cost in energy. It is interesting to note that in type-I $\mathrm{Ba}-\mathrm{Ga}-\mathrm{Ge}$ the energy cost for off-Zintl configurations was found to be significantly higher ${ }^{24}$ than obtained here for BaAl-Ge.

To further examine whether these configurations follow the Zintl prescription, we have calculated their band structures. Selected results for $\mathrm{Ba}_{8} \mathrm{Al}_{15} \mathrm{Ge}_{31}, \mathrm{Ba}_{8} \mathrm{Al}_{14} \mathrm{Ge}_{32}$, and $\mathrm{Ba}_{8} \mathrm{Al}_{12} \mathrm{Ge}_{34}$ are shown in Figs. 4(b)-4(d). Whereas $\mathrm{Ba}_{8} \mathrm{Al}_{16} \mathrm{Ge}_{30}$ in minimized configurations is a semiconductor, ${ }^{19}$ for those with lower $x, E_{F}$ falls above the gap as expected. The calculated results are close to a rigidband model with little change in the band structure while the Fermi level changes with the $\mathrm{Al}$ variation. This is the situation expected in the Zintl model, whereby reduction in $x$ for $x=16$ corresponds to overfilling of framework electron states. Also the fact that the gap remains below $E_{F}$ in these results seems to rule out a transfer of fewer than two electrons from $\mathrm{Ba}$ as a possible explanation of observed nonZintl compositions.

To compare for low $x$, we have also calculated the electronic structure for $\mathrm{Ba}_{8} \mathrm{Ge}_{43}$ in its reported superstructure
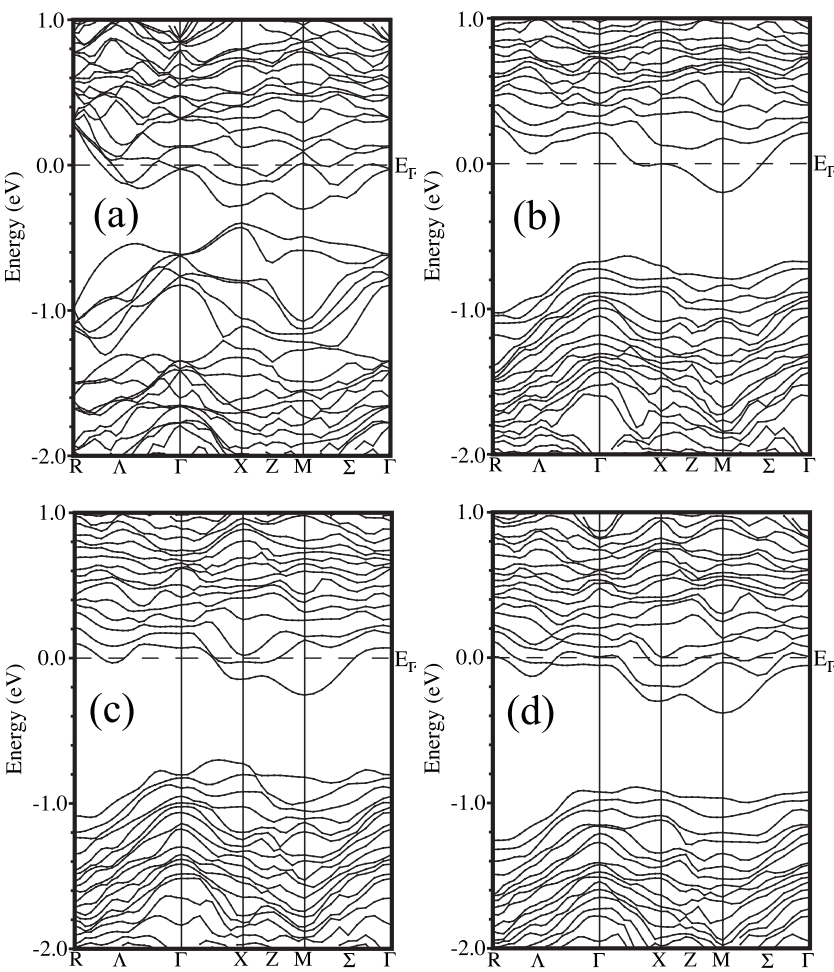

FIG. 4. Band structures for (a) $\mathrm{Ba}_{8} \mathrm{Ge}_{43} \square_{3}$ and the lowest energy configurations of (b) $\mathrm{Ba}_{8} \mathrm{Al}_{15} \mathrm{Ge}_{31}$, (c) $\mathrm{Ba}_{8} \mathrm{Al}_{14} \mathrm{Ge}_{32}$, and (d) $\mathrm{Ba}_{8} \mathrm{Al}_{12} \mathrm{Ge}_{34}$.

configuration. The band structure and density of states (DOS) results are shown in Figs. 4(a) and 5, respectively, with good agreement with recent reports. ${ }^{22,27}$ The labeled upper curve corresponds to the total DOS, and the summed $\mathrm{Ba}$ and $\mathrm{Ge}$ contributions are also shown. (The total DOS also includes a contribution from the interstitial regions, in the full-potential LAPW method.) In $\mathrm{Ba}_{8} \mathrm{Ge}_{43}$ there is a small gap of approximately $0.1 \mathrm{eV}$ appearing below $E_{F}$. The DOS for the $\mathrm{Ba}_{8} \mathrm{Al}_{12} \mathrm{Ge}_{34}$ (Fig. 6), $\mathrm{Ba}_{8} \mathrm{Al}_{15} \mathrm{Ge}_{31}$, and $\mathrm{Ba}_{8} \mathrm{Al}_{14} \mathrm{Ge}_{32}$ (not shown) lowest-energy structures have similar overall broad features where the Ba maximum contribution appears near $7 \mathrm{eV}$. The main differences are the band gap and the location of the Fermi level.

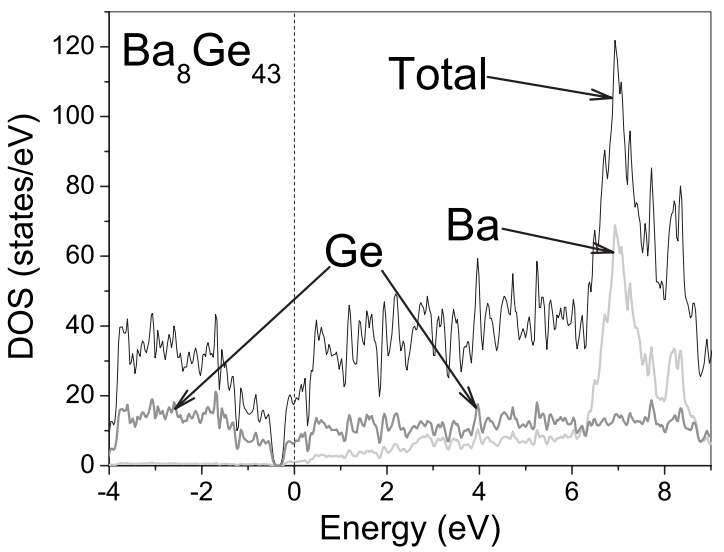

FIG. 5. Total calculated density of states for $\mathrm{Ba}_{8} \mathrm{Ge}_{43}$. Upper curve is the total DOS including the interstitial contribution. Ba and Ge contributions of atoms are also shown as labeled. 


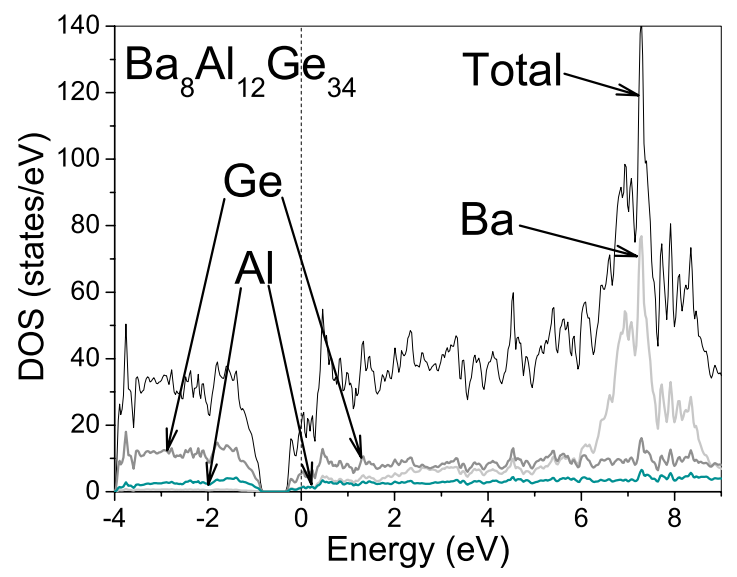

FIG. 6. (Color online) Total calculated density of states for $\mathrm{Ba}_{8} \mathrm{Al}_{12} \mathrm{Ge}_{34}$ in 3-1-8-0 configuration. Upper curve is the total DOS including the interstitial contribution. $\mathrm{Ba}, \mathrm{Ge}$, and $\mathrm{Al}$ contributions of atoms are also shown as labeled.

Interpreting the small gap in $\mathrm{Ba}_{8} \mathrm{Ge}_{43}$ as a boundary between bonding and antibonding states, ${ }^{22}$ it appears that $\mathrm{Ba}_{8} \mathrm{Ge}_{43}$ has an overfilled framework, just as would be expected from an electron-counting argument. Aydemir et al. ${ }^{22}$ speculated that the incomplete Zintl behavior in $\mathrm{Ba}_{8} \mathrm{Ge}_{43}$ is due to a strain destabilization. Their explanation is that the vacancies in the $6 c$ sites might induce excess strain when more than three vacancies per cell are present, limiting their number. The superstructure configuration for $\mathrm{Ba}_{8} \mathrm{Ge}_{43}$ may indeed be one that minimizes strain by avoidance of nearby vacancies; for example, if alternatively attributed to a charge-density wave, the period might be expected to differ in the $\mathrm{Al}_{4}$ sample, with differing charge density. However note that we find the number of vacancies to approach that of $\mathrm{Ba}_{8} \mathrm{Ge}_{43}$ smoothly as $x$ decreases (Fig. 1), rather than reaching a plateau at three vacancies/cell as would be expected if this were a threshold separating configurations with differing strain energy.

We infer that the reduced vacancy count is due to a competition between the formation energy per vacancy and Zintl stabilization energy. Examining Fig. 5 we see that although $E_{F}$ falls above the band gap, it falls within a larger pseudogap approximately $2 \mathrm{eV}$ in width. With $E_{F}$ maintained in this region the number of high-energy occupied states can be kept relatively low while also reducing the number of vacancies that must be formed. Results are similar for other configurations we have calculated; for example, in $\mathrm{Ba}_{8} \mathrm{Al}_{12} \mathrm{Ge}_{34}$ (Fig. 6) although $E_{F}$ appears above the gap it remains in a region of reduced DOS. Thus we infer that the deviation from Zintl behavior may result from balancing the vacancy formation energy vs antibond occupation in the framework, across the range of composition.

\section{CONCLUSIONS}

Several samples with composition $\mathrm{Ba}_{8} \mathrm{Al}_{x} \mathrm{Ge}_{46-x}$ for 4 $\leq x \leq 16$ were synthesized to study the number of vacancies as a function of Al substitution. From WDS and XRD measurements we found that the lattice constant varied smoothly as a function of $\mathrm{Al}$ content with extrapolation to that of $\mathrm{Ba}_{8} \mathrm{Ge}_{43}$ as $x \rightarrow 0$. The vacancy count as a function of $\mathrm{Al}$ concentration also showed a linear behavior with a limiting value of three vacancies as $x \rightarrow 0$ and also remaining below the Zintl curve for large $x$. Resistivities decreased for lower- $x$ samples but with similar shapes, indicating enhanced metallic behavior for low $\mathrm{Al}$ content.

First-principles computations showed that $\mathrm{Ba}_{8} \mathrm{Al}_{16} \mathrm{Ge}_{30}$ with a balanced electron count has the lowest energy, as expected. However configurations with unbalanced electron counts were found to be nearly equivalent in energy and we speculate that the departures from a Zintl model may be due to a competition between framework antibond energies and vacancy formation energies.

\section{ACKNOWLEDGMENTS}

This work was supported by the Robert A. Welch Foundation (Grant No. A-1526) and by the National Science Foundation (Grant No. DMR-0103455).
${ }^{1}$ G. S. Nolas, J. L. Cohn, G. A. Slack, and S. B. Schujman, Appl. Phys. Lett. 73, 178 (1998).

${ }^{2}$ J. L. Cohn, G. S. Nolas, V. Fessatidis, T. H. Metcalf, and G. A. Slack, Phys. Rev. Lett. 82, 779 (1999).

${ }^{3}$ V. L. Kuznetsov, L. A. Kuznetsova, A. E. Kaliazin, and D. M. Rowe, J. Appl. Phys. 87, 7871 (2000).

${ }^{4}$ B. C. Chakoumakos, B. C. Sales, D. G. Mandrus, and G. S. Nolas, J. Alloys Compd. 296, 80 (2000).

${ }^{5} \mathrm{~J}$. H. Ross, Jr. and Y. Li, in Nanoscale Magnetic Materials and Applications, edited by J. P. Liu, E. Fullerton, O. Gutfleisch, and D. Sellmyer (Springer, New York, 2009), p. 105.

${ }^{6}$ E. N. Nenghabi and C. W. Myles, Phys. Rev. B 78, 195202 (2008).

${ }^{7}$ A. F. May, E. S. Toberer, A. Saramat, and G. J. Snyder, Phys. Rev. B 80, 125205 (2009).
${ }^{8}$ K. Suekuni, M. A. Avila, K. Umeo, H. Fukuoka, S. Yamanaka, T. Nakagawa, and T. Takabatake, Phys. Rev. B 77, 235119 (2008).

${ }^{9}$ A. Saramat, G. Svensson, A. E. C. Palmqvist, C. Stiewe, E. Mueller, D. Platzek, S. G. K. Williams, D. M. Rowe, J. D. Bryan, and G. D. Stucky, J. Appl. Phys. 99, 023708 (2006).

${ }^{10}$ E. S. Toberer, M. Christensen, B. B. Iversen, and G. J. Snyder, Phys. Rev. B 77, 075203 (2008).

${ }^{11}$ M. Christensen and B. B. Iversen, Chem. Mater. 19, 4896 (2007).

${ }^{12}$ T. Uemura, K. Akai, K. Koga, T. Tanaka, H. Kurisu, S. Yamamoto, K. Kishimoto, T. Koyanagi, and M. Matsuura, J. Appl. Phys. 104, 013702 (2008).

${ }^{13}$ R. F. W. Herrmann, K. Tanigaki, T. Kawaguchi, S. Kuroshima, and O. Zhou, Phys. Rev. B 60, 13245 (1999).

${ }^{14}$ N. L. Okamoto, K. Kishida, K. Tanaka, and H. Inui, J. Appl. 
Phys. 100, 073504 (2006).

${ }^{15}$ H. Shimizu, T. Iitaka, T. Fukushima, T. Kume, S. Sasaki, N. Sata, Y. Ohishi, H. Fukuoka, and S. Yamanaka, J. Appl. Phys. 101, 063549 (2007).

${ }^{16}$ B. H. Toby, J. Appl. Crystallogr. 34, 210 (2001).

${ }^{17}$ P. Blaha, K. Schwarz, G. K. H. Madsen, D. Kvasnicka, and J. Luitz, Wien2k, An Augmented Plane Wave + Local Orbitals Program for Calculating Crystal Properties (Karlheinz Schwarz, Techn. Universität Wien, Austria, 2001).

${ }^{18}$ W. Carrillo-Cabrera, S. Budnyk, Y. Prots, and Y. Grin, Z. Anorg. Allg. Chem. 630, 2267 (2004).

${ }^{19}$ W. Gou, S. Y. Rodriguez, Y. Li, and J. H. Ross, Jr., Phys. Rev. B 80, 144108 (2009).

${ }^{20}$ G. J. Miller, in Chemistry, Structure, and Bonding of Zintl Phases and Ions, edited by S. M. Kauzlarich (VCH, New York, 1996), p. 1.

${ }^{21}$ C. Candolfi, U. Aydemir, M. Baitinger, N. Oeschler, F. Steglich, and Y. Grin, J. Electron. Mater. http://dx.doi.org/10.1007/ s11664-009-1011-0

${ }^{22}$ U. Aydemir et al., Dalton Trans. 39, 1078 (2010).

${ }^{23}$ J. M. Ziman, Principles of the Theory of Solids (Cambridge University Press, London, 1972).

${ }^{24}$ N. P. Blake, D. Bryan, S. Latturner, L. Mollnitz, G. D. Stucky, and H. Metiu, J. Chem. Phys. 114, 10063 (2001).

${ }^{25}$ S. Y. Rodriguez, X. Zheng, L. Saribaev, and J. H. Ross, Jr., Thermoelectric Materials-Growth, Properties, Novel Characterization Methods, and Applications, MRS Symposia Proceedings No. 1267 (Materials Research Society, Pittsburgh, 2010), p. DD04.07.

${ }^{26}$ E. N. Nenghabi and C. W. Myles, J. Phys.: Condens. Matter 20, 415214 (2008)

${ }^{27}$ Y. Li, Y. Liu, N. Chen, G. Cao, Z. Feng, and J. H. Ross, Jr., Phys. Lett. A 345, 398 (2005). 